\title{
INOVASI DAKWAH MELALUI MULTIMEDIA
}

\author{
Oleh Samsinar S.
}

\begin{abstract}
Dawah multimedia is an innovation of da'wah and breakthrough for the da' $i$ in the running activity propagation in accordance with the demands and needs of the community at this point to pay attention to the development of science and technology today. Dai conveying the Da'wah should use cutting edge media by combining media in preaching good media pulpit, audio, print, internet or the specifics of social media.
\end{abstract}

Kata Kunci : Multimedia, inovasi dakwah

\section{Pendahuluan}

Perkembangan ilmu pengetahuan dan teknologi tidak dapat dihindari dan menjadi sebuah kebutuhan. Perkembangan ini berimbas pada berbagai aspek kehidupan manusia yang menimbulkan efek positif dan negatif. Salah satu aspek yang mempengaruhi perkembangan teknologi yaitu dakwah. Kegiatan dakwah pada masa ini lebih berfokus pada pemanfaatan berbagai media dalam menyampaikan pesan dakwah kepada masyarakat. Oleh karena itu, dai sebagai fasilitator atau mediator dalam membimbing, mengarahkan dan menyerukan amar ma'ruf dan nahi mungkar harus memberdayakan dan memanfaatkan multimedia dalam penyampaian dakwahnya agar tujuan dakwah dapat lebih mudah dicapai.

Edgar Dale dalam Husniyatus Salamah Zainiyati mengemukakan bahwa manusia memperoleh ilmu pengetahuan dari indra lihat sebanyak $75 \%$ dan indra dengar sebanyak $15 \%$, selebihnya dari indra lainnya. Gabungan dari berbagai media yang ada pada multimedia memanfaatkan gabungan dari indra pada manusia untuk pencapaian suatu kompetensi dan tingkat pemahaman bagi individu. ${ }^{1}$ Dengan dai menggunakan multimedia sebagai jembatan penghubung dalam penyampaian dakwahnya maka mad'u sebagai obyek dakwah lebih mudah memahami apa yang disampaikan, lebih menarik dan mad'u tidak bosan dalam menerima pesan dakwah.

Dakwah multimedia merupakan salah satu dakwah masa kekinian yang dapat dinikmati oleh semua orang. Pemanfaatannya sebagai sarana dakwah merupakan salah satu bentuk inovasi dakwah. Pada masa lalu, dakwah identik dengan mimbar, mesjid, mushallah, pengajian dan lainnya. Bahkan saat ini, masih banyak orang yang mengartikan dakwah hanya sebagai kegiatan keagamaan saja, padahal dakwah lebih dari itu. Dakwah berpotensi memberikan motivasi, mengingatkan, mengajarkan, segala hal yang baik dan buruk yang harus diketahui oleh manusia. ${ }^{2}$ Dengan

\footnotetext{
${ }^{1}$ Husniyatus Salamah Zainiyati, Pengembangan Media Pembelajaran Berbasis ICT (Cet. I; Jakarta: Kencana, 2017), h. 171.

${ }^{2}$ Yasril Yazid dan Nur Alhidayatillah, Dakwah dan Perubahan Sosial (Cet.I; Depok: Rajawali Pers, 2017), h. 97.
} 
demikian, dakwah dengan multimedia memberikan kontribusi positif bagi dai dalam menyampaikan pesan dakwahnya dan mad'u dapat lebih mudah menerima dan memahami pesan dakwah melalui multimedia. Oleh karena itu, sebagai bentuk inovasi dakwah, dai harus melek media, menguasai berbagai media dalam berdakwah, tidak sebaliknya gaptek terhadap media sehingga tidak bisa mengikuti perkembangan masa kini.

\section{Pembahasan}

\section{Konsep Media dan Multimedia Dakwah}

Secara etimologis, media berasal dari bahasa Latin, medius yang secara harfiah berarti perantara, tengah atau pengantar. Dalam bahasa Inggris, media merupakan bentuk jamak dari medium berarti tengah, antara dan rata-rata. Dalam bahasa Arab disebut wasilah yang berarti alat atau perantara atau pengantar pesan dari pengirim kepada penerima pesan. ${ }^{3}$ Jadi media adalah alat yang dipakai sebagai perantara atau sebagai penengah dalam melakukan suatu kegiatan.

Multimedia diartikan sebagai lebih dari satu media. Multimedia dapat berupa kombinasi antara teks, grafik, animasi, suara atau video. Penggabungan ini merupakan satu kesatuan yang secara bersama menampilkan informasi atau pesan. ${ }^{4}$ Menurut Chapman dan Chapman dalam I Gde Wawan Sudatha, multimedia sebagai alat penyampai pesan yang dapat dibedakan menjadi dua yaitu online delivery dan offline delivery. Online delivery adalah multimedia yang menggunakan satu jaringan untuk menyampaikan informasi dari komputer atau server machine yang menjadi pusat penyimpan data ke jaringan lain baik jaringan lokal dalam suatu organisasi mauapun jaringan internet. Sedangkan offline delivery adalah multimedia yang disimpan dengan menggunakan suatu alat penyimpan atau kemasan yang dapat dipindahkan. Alat penyimpan tersebut mampu menyimpan data yang besar sesuai dengan ciri-ciri data multimedia misalnya DVD dan CD-ROM. ${ }^{5}$ Philips dalam I Gde Wawan Sudatha juga memberikan pengertian multimedia yang menekankan pada komponen interaktivitas yang merujuk kepada proses pemberdayaan pengguna untuk mengendalikan lingkungan melalui komputer. ${ }^{6}$

Secara terminologis, media dakwah menurut para ahli dapat dikemukakan sebagai berikut :

a. A. Hasjmy, media dakwah merupakan sarana yang digunakan dai dalam berdakwah

b. Hamzah Ya'qub, media dakwah adalah alat objektif yang menjadi saluran yang menghubungkan ide dengan umat

\footnotetext{
${ }^{3}$ Azhar Arsyad, Media Pembelajaran (Cet. XVIII; Jakarta: Rajawali Pers, 2015), h. 3.

${ }^{4}$ Azhar Arsyad, Media Pembelajaran, h. 162.

${ }^{5}$ I Gde Wawan Sudhata dan I Made Tegeh, Desain Multimedia Pembelajaran (Cet. I; Yogyakarta: Media Akademi, 2015), h. 22.

${ }^{6}$ I Gde Wawan Sudhata dan I Made Tegeh, Desain Multimedia Pembelajaran, h. 22.
} 
c. M. Munir dan Wahyu Ilahi, media dakwah adalah alat yang digunakan untuk menyampaikan materi dakwah (ajaran Islam) kepada mad'u (penerima dakwah)

d. Al-Bayanuni, media dakwah adalah sesuatu yang bersifat fisik dan nonfisik yang bisa mengantarkan dai dalam menerapkan strategi dakwah

e. Awaluddin Pimay, media dakwah adalah sarana yang digunakan oleh dai untuk menyampaikan materi dakwah. ${ }^{7}$

Berdasarkan pengertian istilah di atas, maka media dakwah adalah alat atau sarana yang digunakan oleh dai dalam menyampaikan materi dakwahnya kepada mad'u baik yang berbentuk secara fisik maupun nonfisik. Berdasarkan pengertian di atas, maka multimedia dakwah dapat diartikan sebagai kombinasi alat atau sarana yang digunakan oleh dai dalam melaksanakan kegiatan dakwahnya untuk memudahkan pencapaian tujuan dakwah.

Pada masa kehidupan Nabi Muhammad saw., media yang paling banyak digunakan adalah media audio yakni menyampaikan dakwah secara lisan, sikap dan perilaku Nabi juga merupakan media visual yang dapat ditiru atau dilihat oleh mad'u. Dalam perkembangan selanjutnya, terdapat berbagai media dakwah yang efektif, baik berupa media visual, audio, audio-visual, dan sebagainya. Munculnya berbagai media dakwah karena berkembangnya teknologi sehingga penggunaan media harus disesuaikan dengan kebutuhan masyarakat. Oleh karena itu, dai harus menguasai dengan baik multimedia dan memvariasikan medianya dalam berdakwah agar mad'u tidak bosan dengan materi yang disampaikan.

Ada beberapa media atau multimedia yang dapat digunakan dalam menyebarluaskan ajaran-ajaran Islam atau melakukan dakwah yaitu :

a. Media melalui Mimbar

Mimbar merupakan salah satu tempat atau media untuk berdakwah. Seorang dai dapat memanfaatkan mimbar sebagai tempat untuk menyampaikan nilainilai kebaikan, gagasan, dan peringatan tentang kebaikan. Mimbar sebagai media penyampai atau sarana untuk mengajak masyarakat, berinteraksi dengan masyarakat untuk melaksanakan kebaikan sesuai dengan ajaran Islam

b. Media Audio

Media audio merupakan alat yang mengeluarkan bunyi seperti radio, kaset, rekaman dan lainnya. Radio merupakan salah satu sarana berdakwah yang efektif. Apalagi di segala penjuru bisa menjangkau dakwah dengan adanya radio. Bagi masyarakat pada umumnya yang kurang mampu, pasti mengerti dan memahami radio dan fungsinya. Radio pada zaman sekarang sudah hampir tertinggal dengan media lain. Namun, masih efektif dan tepat untuk berdakwah bagi masyarakat yang kurang mampu. Program siaran keagamaan melalui media radio dapat menjangkau seluruh lapisan masyarakat serta dapat menembus ruang dan waktu tanpa batas. Oleh karenanya, harus dikemas

\footnotetext{
${ }^{7}$ Awaludin Pimay, Metodologi Dakwah: Kajian Teoritis dari Khazanah Al-Qur'an (Cet. I; Semarang: Rasail, 2006), h. 36.
} 
dengan baik terutama siaran keagamaan atau dakwah sehingga dapat diterima oleh masyarakat secara lugas, menyenangkan, memiliki daya tarik dan berhasil dan berdaya guna bagi masyarakat. ${ }^{8}$ Media radio sangat penting digunakan dalam berdakwah karena sifatnya langsung, tidak mengenal jarak dan rintangan, memiliki daya tarik yang kuat, relatif murah, tidak terhambat oleh kemampuan membaca dan menulis.

Selain itu, rekaman atau MP3 juga menjadi media audio yang dapat digunakan oleh dai dalam berdakwah. Hasil rekaman dapat diputar ulang dan didengar kembali oleh mad'u. dakwah dengan rekaman harus dipersiapkan sebelumnya baik isi atau materi dakwahnya dan intonasi suara harus jelas. Dai harus mengecek berulang kali agar tidak ada kesalahan dalam melakukan rekaman. $^{9}$

Dengan demikian, media audio juga memberi kontribusi yang penting bagi mad'u, karena setiap mad'u berbeda-beda dalam menerima dakwah. Ada mad'u yang suka dengan media audio karena kecenderungannya lebih suka mendengarkan pesan dakwah dari pada media lainnya, begitu juga sebaliknya.

c. Media Cetak

Pelopor dari media ini adalah Nabi Sulaiman yaitu mempelopori dakwah dengan pena atau dakwah bil qalam. Dalam suatu riwayat disebutkan bahwa surat Nabi Sulaiman kepada Ratu Balqis merupakan surat bercorak dakwah dan komunikasi pertama yang dimulai dengan basmalah. Menurut Ali Yafie dalam Litbang dan Diklat Kemenag RI mengemukakan bahwa dakwah bil qalam pada dasarnya merupakan salah satu media komunikasi untuk menyampaikan informasi tentang Allah, alam, makhluk-makhluk, hari akhir, serta nilai-nilai keabadian hidup. Dakwah model ini merupakan dakwah tertulis melalui media cetak. ${ }^{10}$

Media cetak juga merupakan media yang dapat digunakan oleh dai dalam berdakwah. Dai dapat memanfaatkan media ini sebagai sarana yang baik agar mad'u dapat lebih dekat dengan-Nya.

Yang termasuk media cetak yaitu buku, majalah, poster, brosur, selebaran, dan media lainnya yang dicetak.

Dalam media cetak, dai disarankan menyampaikan materi dakwahnya langsung pada inti pembahasan, menggunakan bahasa yang lugas, cerdas, dan gamblang agar pembaca dapat menangkap isi materi dakwah yang ditulis. ${ }^{11}$ Berdakwah menggunakan sarana media cetak, memerlukan bakat mengarang

${ }^{8} \mathrm{Http}: / /$ arisemangatselalu.blogspot.com/2012/12/strategi-dakwah-melalui-mediaelektronik.html. Diakses pada tanggal 17 Januari 2019.

${ }^{9}$ Moh. Ali Azis, Ilmu Dakwah (Cet. VI; Jakarta: Kencana, 2017), h. 352-354.

${ }^{10}$ Badan Litbang dan Diklat Kementerian Agama Republik Indonesia, Komunikasi dan Informasi: Tafsir Al-Qur'an Tematik (Cet. I; Jakarta: Lajnah Pentashihan Mushaf Al-Qur'an, 2011), h. 162.

${ }^{11}$ Khairi Syekh Maulana Arabi, Dakwah dengan Cerdas: Bekal-Bekal untuk Aktivis Dakwah, h. 46 . 
karena media cetak merupakan sarana komunikasi tulisan. Banyak dai yang mampu berbicara memikat di depan mimbar tetapi tidak mampu menuangkannya dalam sebuah tulisan. Jadi, frekuensi dakwah bil lisan jauh lebih besar dari pada dakwah bil qalam atau tulisan. Akan tetapi, banyak pula dai yang bisa keduanya, di mimbar dan dengan media tulisan atau cetak. ${ }^{12}$

Dakwah dengan media ini memiliki keunggulan yaitu media ini dapat menjangkau masyarakat luas, dai memiliki beban psikologis lebih ringan dibandingkan dengan dai yang langsung menyampaikan secara lisan materi dakwahnya, lebih praktis, dapat dibaca dimana saja dan kapan saja, sehingga memudahkan mad'u untuk menerima pesan dakwahnya.

d. Media Sosial

Media sosial dapat digunakan dalam berdakwah. Media sosial ini seperti facebook, twitter, whatsapp, youtube, dan lainnya dapat dimanfaatkan sebagai ruang untuk menyampaikan pesan dakwah. Media ini memberi peluang bagi dai dalam menyerukan pesan-pesan keagamaan dan nilai-nilai kebenaran dapat dituangkan melalui media ini. ${ }^{13}$

Pada media ini, pesan harus dikemas dengan baik dan tidak terlalu panjang. Pesannya harus singkat, padat dan jelas, sehingga orang yang akan membacanya membaca dengan tuntas dan sebaiknya dapat menggugah emosi atau perasaan orang yang membacanya sehingga mereka tersentuh dan dapat melakukannya sesuai dengan pesan yang disampaikan.

Youtube juga dapat dimanfaatkan oleh dai. Durasi dakwahnya dapat diunggah di youtube, pesan dakwahnya juga harus jelas dan tidak terlalu panjang, apalagi bertele-tele. Dai harus memperhatikan efektivitasnya khususnya waktu yang digunakan dalam penyampaiannya. ${ }^{14}$

Pemanfaatan youtube bagi dai harus memperhatikan materi yang disampaikan, waktu dalam menyampaikannya, dan cara penyampaiannya sehingga pesan yang disampaikan dapat diterima bagi mad'u.

Berbagai media di atas dapat berfungsi secara efektif jika seorang dai mampu menggunakannya dengan baik dengan memperhatikan berbagai hal yang terkait dengan komponen lainnya dalam berdakwah baik materinya, metodenya, mad'unya, dan dai itu sendiri sehingga tujuan dakwah dapat tercapai sesuai dengan apa yang diharapkan oleh dai. Oleh karena itu, dai harus memahami karakteristik media yang akan digunakan dan menyesuaikannya dengan kebutuhan dan situasi dan kondisi mad'u sehingga materi yang disampaikan dapat diterima dan mad'u terpengaruh untuk menjalankan apa yang disampaikan.

${ }^{12}$ Zulkarnain, Dakwah Islam di Era Multimedia dalam Jurnal Risalah, Vol. XXIV, Edisi II, November 2013, h. 39.

${ }^{13}$ Khairi Syekh Maulana Arabi, Dakwah dengan Cerdas: Bekal-Bekal untuk Aktivis Dakwah, h. 44 .

${ }^{14}$ Khairi Syekh Maulana Arabi, Dakwah dengan Cerdas: Bekal-Bekal untuk Aktivis Dakwah (Cet I; Yogyakarta: Laksana, 2017), h. 45. 


\section{Multimedia sebagai Inovasi Dakwah}

Inovasi dakwah merupakan perubahan-perubahan yang dilakukan dalam berdakwah. Inovasi tersebut bisa dilakukan dari segala unsur dakwah seperti materi, metode, dai, media, dan unsur lainnya. Inovasi dakwah menjadi sebuah keharusan. Kemajuan dunia dan segala perubahannya menimbulkan masalah yang sangat kompleks. Oleh karena itu, inovasi dakwah merupakan suatu keharusan untuk mendapatkan hasil optimal baik dakwah multimedia, maupun dakwah melalui pemberdayaan masyarakat. ${ }^{15}$

Dai harus melek media. Perkembangan ilmu pengetahuan dan teknologi menuntut dai untuk mengembangkan ilmu pengetahuan dan penggunaan teknologi dalam menyampaikan dakwahnya kepada masyarakat agar tidak ketinggalan zaman. Menurut Sindhunata dalam Bambang S. Ma'arif bahwa dai yang menguasai multimedia akan mengajak mad'u atau mitra dakwah untuk :

a. Memahami bahwa apa yang disajikan dalam media bukanlah realita secara lahiriah dan apa adanya. Media mengolah dan memproduksikan realita dengan tujuan tertentu. Jadi media adalah suatu kontruksi tentang realitas, dan kontruksi itu ditentukan oleh berbagai determinan

b. Membimbing agar mitra dakwah mengetahui bahwa media adalah salah satu sarana untuk menginterpretasikan realitas. Banyak hal yang ikut menentukan isi dari interpretasi itu. Mitra dakwah tidak perlu mempelajari kekeliruan interpretasi itu, tetapi memperkaya diri dengan kebenaran interpretasi itu

c. Tidak menjadi penerima yang pasif, tetapi menjadi penentu yang aktif bagi apa yang diterimanya melalui media

d. Menyadari bahwa media itu merupakan bisnis yang berorientasi pada profit. Jadi produk media didasari oleh kepentingan ekonomis dari mereka yang memilikinya

e. Kritis terhadap implikasi-implikasi ideologis serta sistem-sistem nilai yang terkandung dalam media sehingga ia terkait dengan iklan

f. Perlu memperhatikan isi atau pesan dalam berdakwah ${ }^{16}$

Dengan demikian, suatu keharusan bagi dai untuk mengembangkan kompetensinya khususnya dalam menguasai media atau multimedia untuk menyampaikan pesan dakwahnya kepada mitra dakwah.

Ada beberapa media yang harus menjadi perhatian bagi dai adalah televisi dan internet, walaupun media lain juga sangat penting. Akan tetapi, media yang banyak digunakan oleh mitra dakwah adalah televisi dan internet. Televisi menjadi media efektif bagi dai dalam menyampaikan dakwahnya. Maraknya dakwah melalui televisi tidak terlepas dari gejala global, segala bentuk komunikasi dapat menjadi profesi

\footnotetext{
${ }^{15}$ Yasril Yazid dan Nur Alhidayatillah, Dakwah dan Perubahan Sosial (Cet.I; Depok: Rajawali Pers, 2017), h. 97.

${ }^{16}$ Bambang S. Ma'arif, Komunikasi Dakwah: Paradigma untuk Aksi (Cet. I; Bandung: Remaja Rosdakarya, 2010), h. 85-86.
} 
yang bersentuhan dengan bisnis, walaupun kenyataan ini sering menjadi kontroversi di masyarakat. ${ }^{17}$ Dengan media ini maka terjadi proses interaksi sosial keagamaan sehingga masyarakat dapat terpengaruh dan menerima dakwah dengan baik.

Internet merupakan media yang mencakup informasi dalam berbagai bidang baik politik, budaya, kejahatan, hukum, pendidikan, kebudayaan, kesehatan, informasi keislaman dan lainnya. Dengan adanya internet, dai dapat menelusuri berbagai informasi setiap saat. Namun, dai harus teliti dan waspada. Sebab, media ini juga dipenuhi informasi-informasi yang kebenarannya masih perlu ditelaah ulang. Dai harus memilah dan memilih portal-portal berita yang informasinya dapat dipertanggungjawabkan. Ketika informasinya benar atau valid maka dai dapat membagikannya melalui media sosial baik whatsapp, facebook atau media sosial lainnya sehingga masyarakat luas dapat mengetahuinya. Bahkan jika perlu dai menggunakan bahasa Internasional dan dibagikan kepada masyarakat Internasional. ${ }^{18}$ Dengan demikian, media ini sangat memberikan dampak positif bagi dai dan mad'u atau penerima dakwah.

Internet memiliki kelebihan sebagai media dakwah yaitu Pertama, sifatnya yang never turn-off (tidak dapat dimatikan) dan unlimited access (dapat diakses tanpa batas). Internet memiliki keleluasaan kepada penggunanya untuk mengakses dalam kondisi dan situasi apapun. Kedua, internet merupakan tempat yang tepat bagi mereka yang ingin berdiskusi tentang pengalaman spiritual yang tidak rasional dan bila didiskusikan di forum akan bisa mengurangi keterbukaannya. Internet menyediakan ruang yang mengakomodasi keinginan seseorang untuk merasa bebas membicarakan sesuatu yang di luar kelaziman ilmiah. Ketiga, sebagian orang memiliki keterbatasan dalam komunikasi sering kali mendapat kesulitan guna mengatasi dahaga spiritual mereka. Padahal mereka ingin sekali berdiskusi dan mendapat bimbingan dari para ulam. Sementara itu, ada sebagian orang yang ingin bertanya atau mau berdebat dengan para ulama atau dai untuk mencari kebenaran, namun kondisi sering tidak memungkinkan. Internet hadir sebagai kawan dan lawan berdiskusi sekaligus jadi pembimbing setia. Oleh karena itu, para ulama atau dai seharusnya dapat menggunakan internet sebagai media efektif untuk mencapai tujuan dakwahnya. ${ }^{19}$

Dakwah dengan multimedia memiliki keunggulan dan keterbatasan. Keunggulannya adalah dapat diakses oleh semua kalangan, dai dapat menyampaikan dakwahnya kapan saja, dimana saja, tanpa harus menyediakan tempat khusus, mad'u bisa memilih tema atau materi sesuai dengan kebutuhannya dan bisa berinteraksi dengan dai secara langsung dan juga bisa lebih akrab dengan dai serta tidak dibatasi jarak, waktu dan tempat. Sedangkan keterbatasannya adalah dai tidak bisa memanfaatkan media massa sebagai media dakwah, mad'u tidak bisa menggunakan media sebagai sarana dakwah (gaptek), banyaknya media yang memberikan materi

\footnotetext{
${ }^{17}$ Wahidin Saputra, Pengantar Ilmu Dakwah (Cet. II; Jakarta: Rajawali Pers, 2012), h. 235.
}

${ }^{18}$ Khairi Syekh Maulana Arabi, Dakwah dengan Cerdas: Bekal-Bekal untuk Aktivis Dakwah (Cet. I; Yogyakarta: Laksana, 2017), h. 163-164.

${ }^{19} \mathrm{http}$ //dinavirginitie.blogspot.com/2012/11/dakwah-artinya-penyiaran-propaganda.html. 
dakwah hanya berdasarkan sudut pandangnya secara pribadi, sumber atau dasar hukum yang dikaji tidak jelas, dan mad'u terkadang menyampaikan pertanyaanpertanyaan dengan kata-kata yang tidak sopan. ${ }^{20}$ Keterbatasan media ini terletak pada ketidak mahiran dai dan mad'u dalam menggunakan media.

Penggunaan multimedia secara efektif dalam berdakwah menjadikan dakwah dapat dilakukan dengan mudah. Kehidupan masyarakat berubah dan lebih mengarah pada ketergantungan atau pemanfaatan media sesuai dengan kebutuhannya.

\section{Kesimpulan}

Salah satu inovasi dalam dakwah adalah penggunaan multimedia dalam aktivitas dakwah. Multimedia dakwah mempunyai peranan yang penting sebagai alat atau media dalam menyampaikan dakwah. Seorang dai harus menggunakan multimedia dalam berdakwah sebagai sebuah strategi agar dakwahnya dapat diterima dengan mudah oleh mad'u dan tujuan dakwah tercapai. Oleh karena itu, dai harus mampu memilih media dakwah sesuai dengan kebutuhan dan kemampuan mad'u. Mad'u masa kini adalah mad'u yang hidup pada zaman teknologi canggih yang membuka sekat dan menghilangkan batas ruang dan waktu sehingga memilih dan menggunakan multimedia merupakan suatu keharusan dan tututan masa kini bagi seorang dai. Dai masa kini adalah dai yang tidak hanya pintar berceramah akan tetapi harus bisa memanfaatkan multimedia dalam dakwahnya. Dengan demikian, penggunaan multimedia merupakan alat bagi keberhasilan dakwah dari seorang dai. Oleh karena itu, dai harus menjadikan multimedia sebagai mitra dalam berdakwah.

\section{Daftar pustaka}

Zainiyati, Husniyatus Salamah. Pengembangan Media Pembelajaran Berbasis ICT. Cet. I; Jakarta: Kencana, 2017.

Yazid, Yasril dan Alhidayatillah, Nur. Dakwah dan Perubahan Sosial. Cet.I; Depok: Rajawali Pers, 2017.

Arsyad, Azhar. Media Pembelajaran. Cet. XVIII; Jakarta: Rajawali Pers, 2015.

Sudhata, I Gde Wawan dan Tegeh, I Made. Desain Multimedia Pembelajaran. Cet. I; Yogyakarta: Media Akademi, 2015.

Pimay, Awaludin. Metodologi Dakwah: Kajian Teoritis dari Khazanah Al-Qur'an. Cet. I; Semarang: Rasail, 2006.

Http://arisemangatselalu.blogspot.com/2012/12/strategi-dakwah-melalui-mediaelektronik.html. Diakses pada tanggal 17 Januari 2019.

Azis, Moh. Ali.Ilmu Dakwah. Cet. VI; Jakarta: Kencana, 2017.

Badan Litbang dan Diklat Kementerian Agama Republik Indonesia. Komunikasi dan Informasi: Tafsir Al-Qur'an Tematik. Cet. I; Jakarta: Lajnah Pentashihan Mushaf Al-Qur'an, 2011.

\footnotetext{
${ }^{20}$ Yasril Yazid dan Nur Alhidayatillah, Dakwah dan Perubahan Sosial, h. 99.
} 
Arabi, Khairi Syekh Maulana. Dakwah dengan Cerdas: Bekal-Bekal untuk Aktivis Dakwah. Cet I; Yogyakarta: Laksana, 2017.

Zulkarnain. Dakwah Islam di Era Multimedia dalam Jurnal Risalah, Vol. XXIV, Edisi II, November 2013.

Ma'arif, Bambang S. Komunikasi Dakwah: Paradigma untuk Aksi. Cet. I; Bandung: Remaja Rosdakarya, 2010.

Saputra, Wahidin. Pengantar Ilmu Dakwah. Cet. II; Jakarta: Rajawali Pers, 2012.

Http://dinavirginitie.blogspot.com/2012/11/dakwah-artinya-penyiaranpropaganda.html. 